and $144(13 \%)$ respectively had a primary intracerebral haemorrhage $\left(\chi^{2}=2.64, \mathrm{P}>0.05\right)$.

The inpatients remained in hospital longer after stroke (median 31 (interquartile range 13-59) days) than the admitted patients (16 (6-43) days). Twenty four (24\%) inpatients returned to their previous residence, compared with $799(63 \%)$ admitted patients (odds ratio $0.19,95 \%$ confidence interval 0.11 to 0.31 ). Sixteen (16\%) inpatients were newly discharged to an institution, compared with $124(10 \%)$ admitted patients (1.77, 95\% confidence interval 0.93 to 3.16 ), which may partly account for the longer stay for inpatients. Sixty $(60 \%)$ inpatients died in hospital, compared with 351 $(28 \%)$ admitted patients $(3.94,95 \%$ confidence interval 2.55 to 6.15$)$; stroke was the primary or secondary cause of death for $51(85 \%)$ inpatients and $301(86 \%)$ admitted patients.

\section{Comment}

Although the inpatients and the admitted patients were similar in terms of age and sex, inpatients stayed in hospital longer, were more likely to die in hospital, and had less well documented risk factors. Improving staff awareness on medical and surgical wards regarding the importance of the early identification and documentation of known risk factors for stroke may improve outcome.

We thank Liz Lightbody, Hazel Dickinson, and Dimitrios Theofanidis, who collected data from the European stroke database, and the BMJ reviewers (Gord Gubitz and M J Campbell) for their comments.

Contributors: NA contributed to the interpretation of the results and to writing the paper. $\mathrm{KMcD}$ analysed the data and contributed to writing the paper. ML advised on and contributed to the statistical analysis and interpretation of the results and to writing the paper. AS contributed to the interpretation of the results and to writing the paper and will act as guarantor for the paper. CW advised on the results, analysis, and interpretation and contributed to writing the paper.

Funding: None.

Competing interests: None declared.

1 Bamford J, Sandercock P, Dennis M, Warlow C, Jones L, McPherson K, et al. A prospective study of acute cerebrovascular disease in the community: the Oxfordshire community stroke project 1981-86: 1 . Methodology, demography and incident cases of first-ever stroke. $/$ Neurol Neurosurg Psychiatry 1988;51:1371-80.

2 Azzimondi G, Nonino F, Fiorani L, Vignatelli L, Stracciari A, Pazzaglia P, et al. Incidence of stroke among inpatients in a large Italian hospital. Stroke 1994;25:1752-4.

3 Mahaffey KW, Granger CB, Sloan MA, Thompson TD, Gore JM, Weaver WD, et al. Risk factors for in-hospital nonhemorrhagic stroke in patients with acute myocardial infarction treated with thrombolysis: results from GUSTO-I. Circulation 1998;97:757-64

(Accepted 5 April 2000)

\title{
Preventing dog bites in children: randomised controlled trial of an educational intervention
}

\author{
Simon Chapman, John Cornwall, Joanne Righetti, Lynne Sung
}

Department of Public Health and Community

Medicine,

University of

Sydney, Sydney,

NSW 2000,

Australia

Simon Chapman

associate professor

Delta Society

Australia, 6/3

Spring Street,

Sydney, NSW 2000,

Australia

John Cornwall

consultant

Joanne Righetti

consultant

Lynne Sung

consultant

Correspondence to: S Chapman

Simonc@pub.health. usyd.edu.au

BMJ 2000;320:1512-3

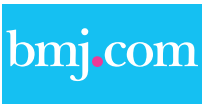

The CONSORT

checklist is

available on the

BMJ's website
Dog bites are a major cause of injury, particularly in children. ${ }^{12}$ Guidelines on prevention are generally unevaluated and include controls on high risk breeds, keeping dogs on a leash, animal training, and educating dog owners. ${ }^{3}{ }^{4}$ However, there are no evaluations of interventions designed to teach people how to avoid being attacked by a dog.

"Prevent-a-Bite" is an educational programme designed for primary school children. ${ }^{5}$ The programme aims to instil precautionary behaviour around dogs, assuming that this might reduce the incidence of attacks. A randomised controlled trial of the efficacy of the intervention was conducted in Australian children aged 7-8 years who were presented with an unsupervised opportunity to approach a strange dog.

\section{Participants, methods, and results}

Eight primary schools in metropolitan Sydney were randomly selected to participate in the trial. All agreed. The schools were cluster randomised into intervention and non-intervention control schools (four in each group), and two classes in each school were then selected to participate. Altogether 346 children aged 7-8 years took part. The study was approved by the human ethics committee of the University of Sydney.
The intervention consisted of a 30 minute lesson conducted by an accredited dog handler. The handler and dog demonstrated various "dos and don'ts" of behaviour around dogs, such as how to recognise friendly, angry, or frightened dogs and how children should approach dogs and owners when they wanted to pat a dog. Children practised patting the dog in the correct manner (that is, asking permission, approaching slowly, extending the hand palm down, patting the dog under the chin and on the chest, avoiding eye contact, walking away slowly and quietly) and precautionary and protective body posture to adopt when approached or knocked over by a dog. They were also told when not to disturb even a friendly, known dog (for example, when it is sleeping, eating, tied up, or in a car). A resource kit for teachers, which included activities to be undertaken before and after the demonstration, was also distributed.

Seven to 10 days after participating in the programme, children in the intervention schools were let out to play unsupervised in the school grounds. A docile Labrador dog was tethered five metres away from its owner, who was disguised as a tradesman. The children were not told that the dog was there and were videotaped by a hidden camera for 10 minutes. Children in control schools were let out to play in similar circumstances, but they had not received the intervention. 


\section{Patting of dogs in intervention and control schools}

\begin{tabular}{lcc} 
& No of children & No (\%) who patted \\
\hline Control schools & & \\
\hline 1 (mixed) & 37 & $19(51)$ \\
\hline 2 (girls) & 31 & $19(61)$ \\
\hline 3 (boys) & 42 & $41(98)$ \\
\hline 4 (boys) & 39 & $39(100)$ \\
\hline Total & 149 & $118(79)$ \\
\hline Intervention schools & & \\
\hline 5 (mixed) & 47 & $8(17)$ \\
\hline 6 (mixed) & 55 & $1(2)$ \\
\hline 7 (mixed) & 36 & $2(6)$ \\
\hline 8 (mixed) & 59 & $18(12)$ \\
\hline Total & 197 & \\
\hline${ }^{*} \chi^{2}=21230, d f=1, P<0.0001$ for intervention versus control schools.
\end{tabular}

The number of children who breached the proscribed behaviours was tallied from the videotape by three authors, one of whom was blind to the intervention or control status of each school. When the three reviewers differed in their scoring of whether an approach to the dog should be recorded as a breach of the guidelines, the videotape was reconsidered and scored as a breach only if all observers agreed.

Children who had received the intervention displayed appreciably greater precautionary behaviour than children in the control schools (table). They were circumspect, typically observing the dog from a distance. Most of the children in the control group (118 of $149,79 \%$ ) patted the dog without hesitation and tried to excite it, while only a few (18 of 197, 9\%) of the children who had received the intervention patted the dog, and they did this surreptitiously or after a considerable period of careful assessment only.

\section{Comment}

The Prevent-a-Bite educational intervention increased appreciably the precautionary behaviour of young children around strange dogs in the short term. Further research is needed to determine whether the programme is able to influence children's behaviour in the longer term, and whether "booster" interventions can help sustain this behaviour, observations in contexts outside school would show a similar magnitude of effect, and wide adoption of the programme would reduce the number of children bitten by dogs.

Contributors: SC designed the study, analysed the video record, wrote the first draft, and is guarantor. JC convened the group that planned and conducted the trial and contributed comments on the paper. JR conducted the intervention, analysed the video record, and helped write the paper. LS organised school participation, analysed the video record, and helped write the paper.

Competing interests: JC, JR, and LS are paid consultants to the Delta Society of Australia. SC has been paid an honorarium and travel expenses for speaking at a meeting about the intervention.

Funding: This study was funded by a small grant to SC's department by the Delta Society Australia Ltd.

1 Thompson PG. The public health impact of dog attacks in a major Australian city. Med J Aust 1997;167:129-32.

2 Sacks JJ, Kresnow M, Houston B. Dog bites: how big a problem? Injury Prev 1996;2:52-4.

3 Bandow JH. Will breed-specific legislation reduce dog bites? Can Vet J 1996;37:478-82.

4 Patrick GR, O'Rourke KM. Dog and cat bites: epidemiologic analyses suggest different prevention strategies. Public Health Rep 1998;113:252-7.

5 The Delta dog safe project. Delta News 1999;No 4:7. www.vetevents.com/ delta/archives/news4j.htm\#story (accessed 10 May 2000).

(Accepted 6 March 2000)

\section{A patient who changed my practice Me, the heartsink patient}

Going back to work was not just hard. It was ridiculously hard. It was the hardest thing I have ever done. I have never considered not working, but I wanted someone to tell me to stop. As my baby approached 4 months, my days, my waking thoughts, and all my conversation became dominated by worry about leaving her. Unsurprisingly, she cried each morning as I dropped her at the nursery in a nearby village. I usually recovered from my own drenching panic as I approached a particular cottage garden in the next village on my journey to work.

A year later I found myself in the ladies' cloakroom deep in the maze that is St Mary's Medical School. This is a strangely shaped cubbyhole with mirrors on two walls. I glimpsed my profile and got a shock. I changed my hairdresser but the possibility of myxoedema did not enter my head.

Life remained a struggle. Finances improved, so I could work less. Having a baby had apparently dented my brain permanently and I wasn't very comfortable in public health. I passed the membership of the Faculty of Public Health Medicine and crept back to clinical medicine. I was a remarkably regular attender at my doctor's surgery for a variety of minor complaints. My vague "acopia," the ebbing of my confidence, my gradually increasing bulk, and my mad-professor hair all became part of me. Patients could hear the cogs clicking as I groped towards decisions. Family and friends knew all about my struggles with domestic

management and parenting, my daytime naps, and early nights.

Breastfeeding my second daughter seemed to help. I happily accepted a part time partnership in general practice, but, as she approached 2, facing any task, from getting dressed to doing a consultation, seemed like a steep hill to climb. I grasped some self confidence from somewhere and finally described to my doctor what "tired all the time" meant for me. I asked if she could check my thyrotropic hormone, just in case. I have a strong family history.

If I did know that there is a link between postnatal mood disturbance and thyroid disease I had forgotten. ${ }^{1}$ Now I check the thyroid function of all mums with postnatal depression or who are overly concerned about their baby. My spell of tiredness has led me to investigate and investigate my heartsink patients.

Thyroxine is giving me back my energy. Surgeries are enjoyable again, housework achievable, and potty training possible. My challenge is to find how I can repay my older daughter, 7 years old now, for growing up with a permanently exhausted mother.

Sarah Evans general practitioner,Tring, Hertfordshire

1 Harris B, Othman S, Davies JA, Weppner GJ, Richards CJ, Newcombe RG, et al. Association between postpartum thyroid dysfunction and thyroid antibodies and depression. BMJ 1992;305:152-6.

We welcome articles of up to 600 words on topics such as A memorable patient, A paper that changed my practice, My most unfortunate mistake, or any other piece conveying instruction, pathos, or humour. If possible the article should be supplied on a disk. Permission is needed from the patient or a relative if an identifiable patient is referred to. We also welcome contributions for "Endpieces," consisting of quotations of up to 80 words (but most are considerably shorter) from any source, ancient or modern, which have appealed to the reader. 